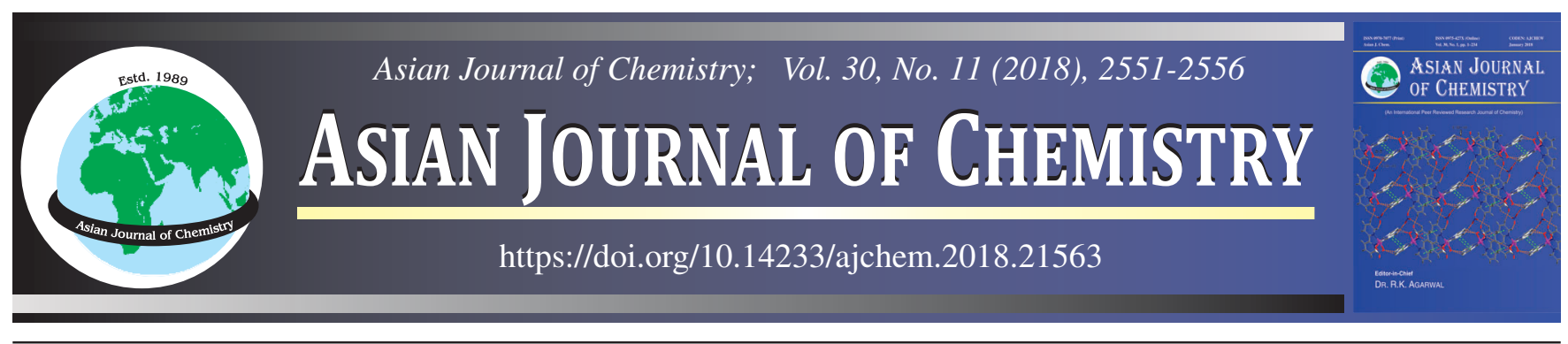

\title{
Differentiation of Immediate and Delayed Metabolic Biomarkers: Qualitative Assessment of Benzene Exposure in Cigarette Smokers and Petrol Station Workers
}

\section{Astitva Anand and RakHi Agarwal*}

Laboratory of Analytical and Molecular Toxicology (Forensic Chemistry and Toxicology Laboratory), Institute of Forensic Science, Gujarat Forensic Sciences University, Gandhinagar-382 007, India

*Corresponding author: E-mail: lamt.dct.gfsu@gmail.com

Received: 6 July 2018; Accepted: 14 August 2018; Published online: 27 September 2018;

Benzene is queen of organic chemistry. It is a precursor molecule, widely used for synthesis and manufacturing of various chemicals for human use. Benzene exposure to humans is inevitable due to its omnipresence. Cigarette smokers and petrol station workers are most common population of benzene exposure/poisoning. Cigarette smokers accounts for half of exposure population globally. Benzene metabolism develops toxic and carcinogenic metabolites, which are acidic and phenolic in nature. Detection of benzene poisoning can only be done by specific methods because of varied nature of its metabolites. These metabolites can be identified by spectroscopic and chromatographic methods. Present work includes the screening of benzene metabolites from human urine sample by ultra performance liquid chromatography (UPLC) with two different detectors. During UPLC analysis, photo diode array detector (PDA) was hyphenated with florescence detector (FLD). Injector port silylation (IPS) was further carried out for gas chromatography-mass spectrometry (GCMS) analysis for confirmation of the obtained results. Liquid-liquid microextraction method was applied to acquire metabolites of benzene from matrix (urine). The UPLC method is more rapid, specific and provides triple confirmation for the screening of benzene metabolites in benzene exposure/poisoning incidences for diagnosis and clinical investigations. Developed method was applied on cigarette smokers and petrol station workers for biomarkers differentiation. The method is readily available for differentiation of immediate and delayed benzene urinary metabolic biomarkers for qualitative assessment/screening of benzene exposure in exposed population.

| Keywords: Cigarette smokers, Petrol station workers, Benzene metabolites, Urine, UPLC-PDA-FLD.

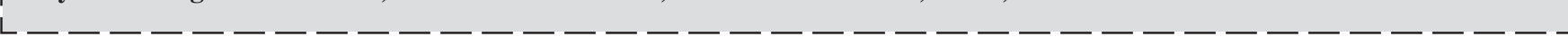

\section{INTRODUCTION}

Benzene is known an omnipresent pollutant, a common industrial chemical and a prominent constituent of gasoline, tobacco smoke and engine emission $[1,2]$. Human population exposes to benzene includes petrochemical workers, petrol station attendants, glue workers, rubber industry workers and smokers etc. [1,3]. In 1987, Classification of International Agency for Research on Cancer (IARC) depicts benzene as a group-I carcinogen [4]. Exposure to benzene results in aplastic anemia, dysfunction of the immune system and leukemia [5]. Benzene is naturally occurring component of petroleum products and present in gasoline (petrol), thus petrol station workers are most likely to be affected from benzene toxicity [6]. Rahman et al. [7] and Barbera et al. [8] have reported benzene poisoning when benzene is stupefied with ethyl alcohol in medico-legal poisoning like accidental and homicidal cases.
For suicidal purpose benzene poisoning is also reported in Agency for Toxic Substances and Disease Registry [9]. Benzene metabolites present in blood, urine or adipose tissues are mostly phenolic and acidic in nature and represents haematotoxic and carcinogenic behaviour of benzene [10]. Seven metabolites of benzene viz. phenol (PH), hydroquinone (HQ), pyrocatechol (PC), 1,2,4-trihydroxy benzene (THB), t,t-muconic acid (MA) and S-phenyl mercaptopuric acid (SPMA) are reported to be excreted from urine $[11,12]$. On the basis of chemical structures benzene metabolites depicts different polarities. In organic chemistry, phenols are less polar than acids, but phenolic benzene metabolites are more polar than acidic metabolites. Phase-II metabolism of benzene suggests that phenolic metabolites are less capable of producing glucuronide conjugates $[13,14]$. Protein, bone marrow, tissue and DNA binding of phenolic metabolites is lesser compared to acidic metabolites during and after biotransformation [14]. Determination of these benzene

This is an open access journal, and articles are distributed under the terms of the Creative Commons Attribution-NonCommercial 4.0 International (CC BY-NC 4.0) License, which allows others to copy and redistribute the material in any medium or format, remix, transform, and build upon the material, as long as appropriate credit is given and the new creations are licensed under the identical terms. 
metabolites can account as major footprint for benzene toxicity in industrial/occupational toxicological studies for monitoring purpose [15]. For rapid qualitative assessment of benzene metabolites in large population exposed to benzene as toxicant became very important and this can only be achieved by regular monitoring of benzene metabolites from urine of occupationally exposed humans and in poisoning cases. For this purpose, a range of techniques has been reported for separation, identification and quantitation of the benzene metabolites [16]. However they are time consuming in terms of overall analysis which as it includes derivatization step, thus, not suitable for rapid screening in large number of samples. Investigation of benzene exposed population in context of metabolomics using chromatographic techniques is highly important. Till date, various techniques have been used for analysis of benzene metabolites in human blood, urine and tissues [17]. Recently, we have reported thin layer chromatography method for separation and further quantitation by UV-visible spectroscopy for phenolic benzene metabolites [18]. Present work includes the detection of benzene metabolites using UPLC-PDA-FLD and then their mass spectrometric confirmation with IPS-GCMS techniques for diagnosis and clinical investigation purposes in benzene poisoning cases. Qualitative method for rapid screening of benzene metabolites from urine samples has been developed using ultra performance liquid chromatography. Retention time and response area from florescence detector has been considered as key parameters for detection and screening. GC-MS method was used for confirmation of metabolites in the samples.

\section{EXPERIMENTAL}

Standards of 6 benzene metabolite viz. phenol, pyrocatechol, hydroquinone and 1,2,4-benzene triol (trihydroxy benzene), t,t-muconic acid and S-phenyl mercaptopuric acid were procured from Sigma-Aldrich (USA). BSTFA + TMCS silane as Silylating reagent was procured from Sigma-Aldrich (USA). Solvents were purchased from Emplura Merck, Germany. Ultrapure water was obtained through Milli-Q water purification system (Millipore, USA). Sterile Uricol were purchased from HiMedia Laboratories (India). All chemical used during experimentation were of analytical grade with high purity.

Sample collection: Urine samples from petrol station workers and cigarette smokers (total 50 no.) were collected randomly from different parts of Gandhinagar city, Gujarat (India) with their consent. Samples were collected from same age range persons of males around 25-30 years. Time of exposure is decided on the basis of their occupation history as petrol station workers. Cigarette smokers who consumes more than 5 years were considered for the studies. E-cigarette smokers were found and urine samples were taken regardless of age and time of smoking. For Study 1, first 25 samples from petrol station workers (10), cigarette smokers (10) and E-cigarette smokers (5) were collected immediately after $1 \mathrm{~h}$ of the exposure. For Study 2, another 25 samples were taken after cessation period of 2 days of exposure from same subjects. Sample did not contain any visible suspended solids. All samples were stored in uricol in refrigerator at $4{ }^{\circ} \mathrm{C}$ till analysis.
Standard preparation: Solutions $(10 \mathrm{~mL})$ of each metabolite standard were prepared at a concentration of $10 \mu \mathrm{g} / \mathrm{mL}$ in methanol. Mixture standard of benzene metabolites was prepared by combining individual solutions to form solution with concentration $10 \mu \mathrm{g} / \mathrm{mL}$. All solutions were stored at 4 ${ }^{\circ} \mathrm{C}$. Fresh and calibrated volumetric flasks and micropipette were used for entire study. All standards were freshly prepared on daily basis to avoid the oxidation.

Liquid-liquid microextraction: For the development of the method, ultra pure HPLC water was used after spiking of benzene metabolites standard, followed by their addition in control urine sample. All extraction and dilution work were carried out in dark in order to avoid sun light. Urine sample $(0.5 \mathrm{~mL})$ was taken into $4 \mathrm{~mL}$ glass vial and digested using 50 $\mu \mathrm{L}$ of concentrated hydrochloric acid. Liquid-liquid micro extraction (LLME) was done using $1.5 \mathrm{~mL}$ ethyl acetate as extraction solvent [18]. Extraction was done by vortexing the urine and extraction solvent mixture for $2 \mathrm{~min}$. Organic layer was collected using micropipette in separate micro centrifuge tube and kept for analysis. Organic layer was completely evaporated under $\mathrm{N}_{2}$. Finally, $500 \mu \mathrm{L}$ methanol was added and mixed to reconstitute the extracted metabolite(s). Methanolic extract $100 \mu \mathrm{L}$ was taken into glass inserts and kept in UPLC vial for analysis. Another $100 \mu \mathrm{L}$ was taken into microcentrifuge tube, evaporated and then reconstituted with $100 \mu \mathrm{L}$ acetonitrile and transferred in $\mathrm{GC}$ vial for analysis. Reconstitution with acetonitrile is preliminary requirement for silylation because methanol reacts with silylating reagent and does not allow metabolites to be derivatized.

Ultra high performance liquid chromatography: Autosampler equipped Shimadzu UPLC model Nexera2 with PDA and FLD detector was used for the study with standardized conditions. A volume of $1 \mu \mathrm{L}$ was taken by autosampler. Fast LC column built in with Shim Pack $C_{18}$ filled $100 \mathrm{~mm} \times 2 \mathrm{~mm}$ ID was used to carry out separation. Equilibration of column was done with (A) $50 \%$ methanol (100\%) and (B) $50 \%$ acetic acid $(0.5 \%$ prepared in ultrapure water) with flow rate $1 \mathrm{~mL} / \mathrm{min}$ and oven temperature $40{ }^{\circ} \mathrm{C}$. The UPLC system was controlled by LC solutions software for the entire study. Scanning of $\lambda_{\max }$ was done between the range of 190-800 $\mathrm{nm}$ in PDA detector. Florescence detector is hyphenated with PDA detector. For this purpose column end connector is joined with PDA detector first and then, PDA end connector is joined with florescence detector. Both detectors were operated simultaneously. Florescence was measured at two different part of phenolic and acidic metabolites. With the aim to get first chromatogram of phenolic metabolites, excitation and emission wavelengths were kept at 260 and $305 \mathrm{~nm}$, respectively. For second chromatogram of acidic metabolites, excitation and emission wavelengths were kept at 395 and $470 \mathrm{~nm}$, respectively. For study 1 and study 2, UPLC-PDA-FLD method was applied for screening of metabolites in both standard and urine. As per guidelines of ICH (International Conference on Harmonization) for identification or qualitative analysis, the method has to be evaluated for its specificity. Therefore, individual standards of 6 metabolites ( $10 \mathrm{ppm}$ concentrations of each) and a mixture of all (10 ppm concentrations of each) were run for retention time confirmation. To get the specificity of detected metabolites 
with respect to their quantity, 2 different concentrations viz. 1 and 10 ppm were run for all metabolic standards individually to obtain the difference between their respective peak area and height on chromatogram.

Modified method for gas chromatography mass spectrometry: An aliquot $1 \mu \mathrm{L}$ from the GC vial was injected by autosampler and separated under standardized conditions. $\mathrm{GC}$ vial was filled with $100 \mu \mathrm{L}$ of analytes in acetonitrile and $100 \mu \mathrm{L}$ of BSTFA + TMCS (99:1) as silylating reagent for injector port silylation (IPS). Perkin Elmer Clarus 680 with MS detector SQ-8 was used for metabolite analysis which was equipped with Elite-5-MS capillary column $(30 \mathrm{~m} \times 0.25 \mathrm{~mm}$ ID $\times 0.25 \mu \mathrm{m}$ film thickness of $5 \%$ phenyl and $95 \%$ dimethyl polysiloxane as the stationary phase). GC-MS system was operated using Turbo Mass Software. Injector port temperature was kept at $250^{\circ} \mathrm{C}$. Initially, the split kept off, then after $5 \mathrm{~min}$, it was kept on with flow of 10:1 $\mathrm{mL} \mathrm{min}^{-1}$. Helium was used a carrier gas with flow rate of $1 \mathrm{~mL} \mathrm{~min}^{-1}$. The GC oven temperature was programmed as follows: $50{ }^{\circ} \mathrm{C}$ hold for $5 \mathrm{~min}$ and

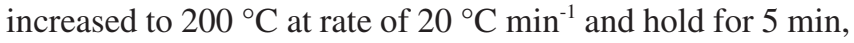
then $280{ }^{\circ} \mathrm{C}$ at rate of $10^{\circ} \mathrm{C} \mathrm{min}^{-1}$ and hold for $5 \mathrm{~min}$. Electron ionization (EI) technique was used for ionization purpose. The ion source and GC inlet temperature were kept at 220 and 280 ${ }^{\circ} \mathrm{C}$, respectively. Qualitative studies were performed in SIR (single ion reaction) mode. GC-MS method was applied to confirm the occurrence of metabolites in both standard and urine [19].

\section{RESULTS AND DISCUSSION}

UPLC-PDA-FLD: Despite the fact of its high toxicity, benzene is widely used as an intermediate compound in the manufacturing of numbers of chemicals, including ethyl benzene, cumene, cyclohexane, nitrobenzene etc. thus, human exposure to benzene is inevitable. In present study, from liquid chromatographic analysis with all six standards, it was found that all metabolites were separated and identified with specific reten- tion time for respective standards. All metabolites were eluted within 6 min through PDA detector with $\lambda_{\max } 216 \mathrm{~nm}$, the retention time for MA, PH, HQ, SPMA, PC and THB were found 1.942, 2.355, 3.435, 3.930, 5.091, $5.582 \mathrm{~min}$, respectively (Fig. 1). Greenlee et al. [20] have reported separation of four phenols viz. PH, PC, HQ and THB using high pressure liquid chromatography with retention time of approximately 13 min. Determination of metabolites from urine of mice using solid phase extraction method followed by HPLC was done within $10 \mathrm{~min}$, where phenol has longest retention time [21]. In present study, PDA detector helps towards identification of wavelength for individual functional group present in the molecular structure. Being advantageous, scanned PDA data after completion of run allowed us to extract data for selected wavelength. Four phenolic metabolites were set up at $270 \mathrm{~nm}$ and two acidic metabolites were set up at $390 \mathrm{~nm}$ to achieve their optimum height. The obtained peaks were confirmed with the presence of their respective functional groups. Retention time for 6 metabolites is almost same in both PDA and FLD detectors as because of very high pressure in UPLC system (Figs. 2 and 3). High pressure permitted very fast travelling of six metabolites from both detectors. During florescence measurement, metabolites were found with very high $\mathrm{mV}$ peak areas with respect to PDA peak area, which reflects higher sensitivity of florescence detector, which provide confirmation for all metabolites (Figs. 2 and 3). Fluorochrome moieties (benzene ring) present in benzene metabolites has identical excitation and emission wavelengths of electrons. This demonstrates the application of florescence detector for assessment of benzene metabolites from urine samples. In muconic acid, there is absence of benzene ring, thus peaks are relatively smaller with respect to other 5 metabolites (Fig. 3). For confirmation of the obtained data, the same samples were run in triplicates. Application of two different detectors proves the presence of metabolites in standards and urine extract. PDA detector is helpful for the analysis of compound of interest by their specific wavelengths. FLD detector identifies compounds
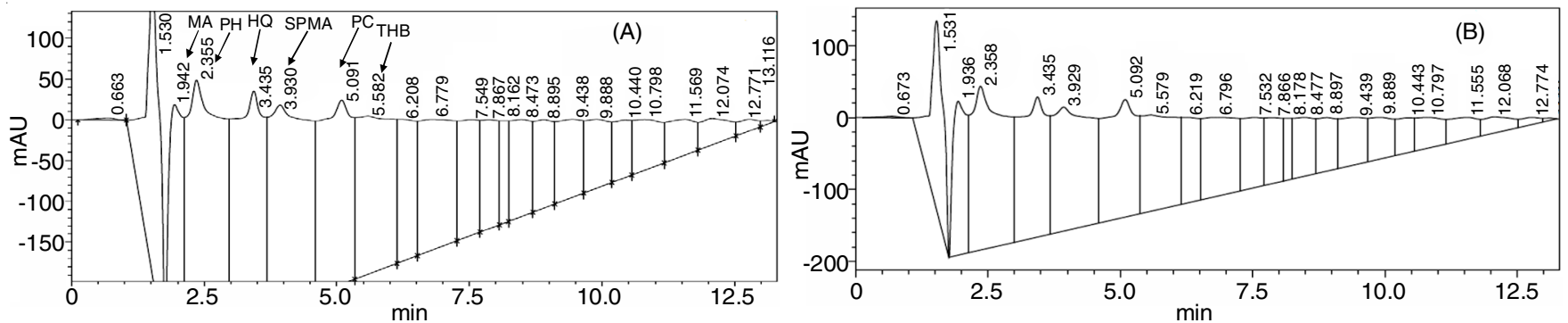

Fig. 1. UPLC-PDA chromatogram of six urinary benzene metabolites (10 ppm) at $216 \mathrm{~nm}$, (A) standard (B) spiked urine
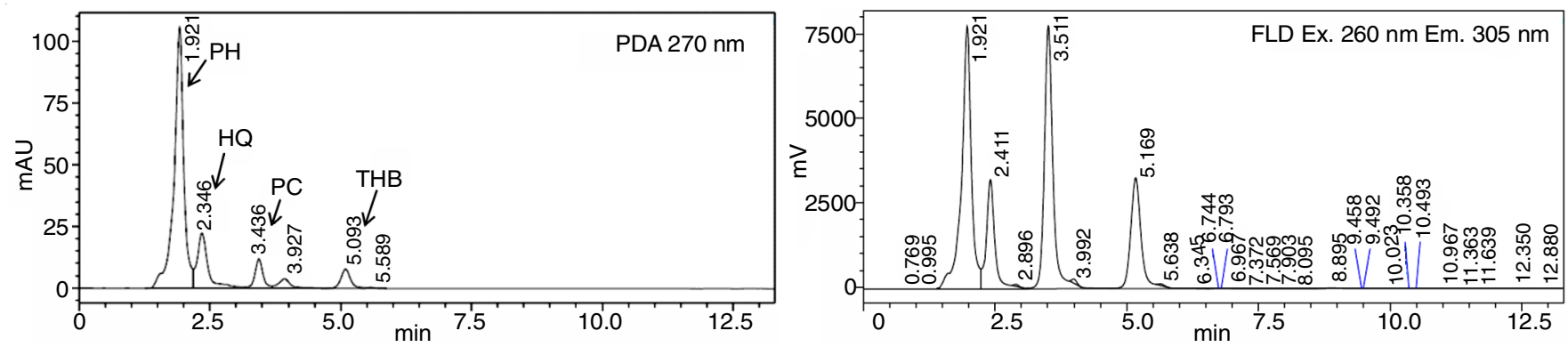

Fig. 2. UPLC-PDA-FLD chromatograms for four phenolic metabolites 

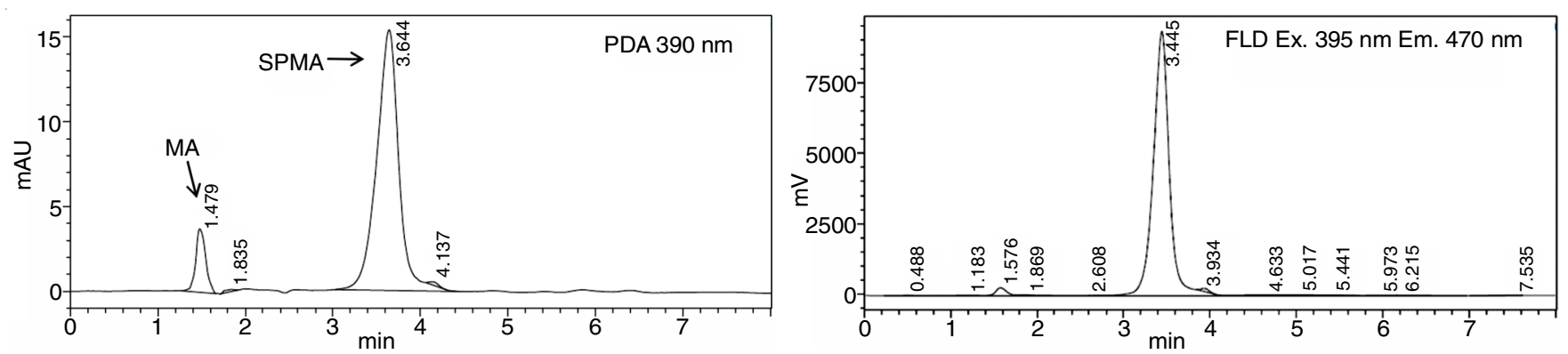

Fig. 3. UPLC-PDA-FLD chromatograms for two acidic metabolites

by their excitation and emission wavelengths. These wavelengths are identical in both detectors with respect to metabolites.

IPS-GC-MS: Prior to UPLC analysis, GC-MS analysis was done for confirmation whether, benzene metabolites present in the samples or not [19]. Injector post silylation is helpful technique as it is fast and less amount of derivatizing reagent is required. It has also a wide range of advantages over the in-vial silylation which make its cost effective technique [22]. Injector port silylation allowed benzene metabolites to be in an identifiable manner since their derivatized products have unique molar masses which confirm the presence of benzene metabolites in the form of their specific silane derivatized products. Gas chromatographic studies show that 6 metabolites were separated at specific retention time [19]. Derivatized products were confirmed with $\mathrm{m} / \mathrm{z}$ values obtained from mass spectrum. For confirmation purpose, same samples were run in triplicates. Waidyanatha et al. [11] have reported separation of 6 metabolites using gas chromatography, while
Rothman et al. [23] have reported separation of 3 phenols and muconic acid.

Qualitative assessment of UBM from real urine samples: The developed method has been successfully applied on human urine samples for identification purpose, further it is useful for analysis of benzene metabolites in poisoning cases. The developed method was performed with 50 human urine samples to identify the presence of benzene metabolites in suspected exposed population (Table-1). First study suggests that the petrol station workers and cigarette smokers have all benzene metabolites. However trihydroxybenzene were not detected in few samples. E-cigarette smokers do not have exposure to benzene directly, thus except phenol no metabolites were found in all 5 samples, presence of phenol (in 2 urine samples) might be due to metabolism of phenolic food commodities consumed by subjects. The data of second study provides the information for the presence of benzene metabolites after cessation of exposure (Table-2). It was found that all phenolic metabolites were absent, whereas acidic metabolites were still

\begin{tabular}{|c|c|c|c|c|c|c|c|}
\hline \multicolumn{8}{|c|}{$\begin{array}{c}\text { TABLE-1 } \\
\text { UPLC-PDA-FLD RESULTS FOR PRESENCE OF BENZENE METABOLITES IN } \\
\text { REAL URINE SAMPLES IMMEDIATE AFTER EXPOSURE }\end{array}$} \\
\hline \multicolumn{2}{|c|}{ Analytes } & Phenol & Pyrocatechol & Hydroquinone & $\begin{array}{c}1,2,4- \\
\text { Trihydroxy } \\
\text { benzene }\end{array}$ & $\begin{array}{l}\mathrm{t}, \mathrm{t}-\mathrm{Muconic} \\
\text { acid }\end{array}$ & $\begin{array}{l}\text { S-Phenyl } \\
\text { mercaptopuric } \\
\text { acid }\end{array}$ \\
\hline \multirow{10}{*}{$\begin{array}{l}\text { Petrol station } \\
\text { workers }\end{array}$} & Sample 1 & Absent & Present & Absent & Present & Present & Present \\
\hline & Sample 2 & Present & Present & Present & Absent & Present & Present \\
\hline & Sample 3 & Present & Present & Present & Present & Present & Present \\
\hline & Sample 4 & Absent & Present & Present & Present & Present & Present \\
\hline & Sample 5 & Present & Present & Present & Absent & Present & Present \\
\hline & Sample 6 & Present & Present & Present & Present & Present & Present \\
\hline & Sample 7 & Present & Present & Present & Present & Present & Present \\
\hline & Sample 8 & Present & Present & Present & Absent & Present & Present \\
\hline & Sample 9 & Present & Present & Present & Present & Present & Present \\
\hline & Sample 10 & Present & Present & Present & Absent & Present & Present \\
\hline \multirow{10}{*}{$\begin{array}{l}\text { Cigarette } \\
\text { smokers }\end{array}$} & Sample 1 & Present & Present & Present & Present & Present & Present \\
\hline & Sample 2 & Present & Present & Present & Present & Present & Present \\
\hline & Sample 3 & Present & Present & Present & Present & Present & Present \\
\hline & Sample 4 & Present & Present & Present & Absent & Present & Present \\
\hline & Sample 5 & Present & Present & Present & Present & Present & Present \\
\hline & Sample 6 & Present & Present & Present & Present & Present & Present \\
\hline & Sample 7 & Present & Present & Present & Absent & Present & Present \\
\hline & Sample 8 & Present & Present & Present & Present & Present & Present \\
\hline & Sample 9 & Present & Present & Present & Absent & Present & Present \\
\hline & Sample 10 & Present & Present & Present & Present & Present & Present \\
\hline \multirow{5}{*}{$\begin{array}{l}\text { E-Cigarette } \\
\text { smoker }\end{array}$} & Sample 1 & Absent & Absent & Absent & Absent & Absent & Absent \\
\hline & Sample 2 & Absent & Absent & Absent & Absent & Absent & Absent \\
\hline & Sample 3 & Present & Absent & Absent & Absent & Absent & Absent \\
\hline & Sample 4 & Absent & Absent & Absent & Absent & Absent & Absent \\
\hline & Sample 5 & Present & Absent & Absent & Absent & Absent & Absent \\
\hline
\end{tabular}




\begin{tabular}{|c|c|c|c|c|c|c|c|}
\hline \multicolumn{8}{|c|}{$\begin{array}{c}\text { TABLE-2 } \\
\text { UPLC-PDA-FLD RESULTS FOR PRESENCE OF BENZENE METABOLITES IN REAL } \\
\text { URINE SAMPLES AFTER CESSATION OF EXPOSURE (PERIOD OF TWO DAYS) }\end{array}$} \\
\hline \multicolumn{2}{|c|}{ Analytes } & Phenol & Pyrocatechol & Hydroquinone & $\begin{array}{c}1,2,4- \\
\text { Trihydroxy } \\
\text { benzene }\end{array}$ & $\begin{array}{l}\mathrm{t}, \mathrm{t}-\text { Muconic } \\
\text { acid }\end{array}$ & $\begin{array}{c}\text { S-Phenyl } \\
\text { mercaptopuric } \\
\text { acid }\end{array}$ \\
\hline \multirow{10}{*}{$\begin{array}{l}\text { Petrol station } \\
\text { workers }\end{array}$} & Sample 1 & Absent & Absent & Absent & Present & Present & Present \\
\hline & Sample 2 & Absent & Absent & Absent & Absent & Present & Present \\
\hline & Sample 3 & Present & Absent & Absent & Absent & Present & Present \\
\hline & Sample 4 & Absent & Absent & Absent & Present & Present & Present \\
\hline & Sample 5 & Present & Present & Present & Absent & Absent & Present \\
\hline & Sample 6 & Present & Absent & Absent & Absent & Present & Present \\
\hline & Sample 7 & Absent & Absent & Present & Absent & Present & Present \\
\hline & Sample 8 & Present & Present & Present & Absent & Present & Absent \\
\hline & Sample 9 & Present & Absent & Present & Present & Present & Present \\
\hline & Sample 10 & Absent & Present & Absent & Absent & Present & Present \\
\hline \multirow{10}{*}{$\begin{array}{l}\text { Cigarette } \\
\text { smokers }\end{array}$} & Sample 1 & Absent & Present & Present & Present & Present & Present \\
\hline & Sample 2 & Absent & Absent & Present & Present & Present & Present \\
\hline & Sample 3 & Absent & Absent & Present & Absent & Present & Present \\
\hline & Sample 4 & Absent & Present & Absent & Absent & Present & Present \\
\hline & Sample 5 & Absent & Absent & Absent & Absent & Present & Present \\
\hline & Sample 6 & Present & Present & Absent & Absent & Present & Present \\
\hline & Sample 7 & Present & Present & Absent & Absent & Absent & Present \\
\hline & Sample 8 & Present & Present & Present & Absent & Present & Present \\
\hline & Sample 9 & Present & Absent & Present & Absent & Present & Present \\
\hline & Sample 10 & Present & Present & Present & Present & Present & Present \\
\hline \multirow{5}{*}{$\begin{array}{l}\text { E-cigarette } \\
\text { smoker }\end{array}$} & Sample 1 & Absent & Absent & Absent & Absent & Absent & Absent \\
\hline & Sample 2 & Absent & Absent & Absent & Absent & Absent & Absent \\
\hline & Sample 3 & Present & Absent & Absent & Absent & Absent & Absent \\
\hline & Sample 4 & Absent & Absent & Absent & Absent & Absent & Absent \\
\hline & Sample 5 & Present & Absent & Absent & Absent & Absent & Absent \\
\hline
\end{tabular}

remains in urine samples. This is because of the more polarity of phenolic metabolites, than acidic metabolites of benzene. Therefore, phenolic metabolites excrete fast than acidic metabolites. Thus, screening and identification of phenolic metabolites can served as immediate biomarkers in benzene exposure whereas acidic metabolites could be an important delayed benzene urinary metabolic biomarkers for qualitative assessment/screening of benzene exposure in exposed population.

Injector port silylation with gas chromatography has dual advantage like no degradation of derivatized products and fasten the analytical method. Silylation helped for higher thermo stability of metabolites after derivatization. Chromatographic behaviours like detection ability and volatility were also smoothen $[24,25]$. SIR mode in mass spectrometry provides the very sensitive detection and confirmation of the same positive ion of the trimethylsilyl-derivatives of benzene metabolites. Hyphenation of UPLC-PDA with FLD detector has higher performance in yielding high resolution and faster speed. Thus, became excellent tool in analysis of metabolites. The chromatograms were accommodated with 6 metabolites within $6 \mathrm{~min}$, which provided the fast screening for all 6 benzene metabolites. The developed method will find wide applications for the analysis of urinary benzene metabolites in various samples for the screening of benzene exposure in environmental and toxicological laboratories for diagnosis and forensic investigation purposes.

\section{Conclusion}

Present study provides a novel, rapid and specific method for qualitative assessment of benzene metabolites as urinary biomarkers using ultrahigh performance liquid chromatography. The method has promising role on routine monitoring of benzene exposure by confirming the presence of six metabolites. The experimental data and results confirms the differentiation of immediate and delayed metabolic biomarkers on the basis of their nature, properties and their excretion behaviour in urine. This proves phenolic metabolites are immediate, while acidic metabolites are delayed biomarkers of phase-I benzene metabolism.

\section{ACKNOWLEDGEMENTS}

The authors are thankful to the Director General of Gujarat Forensic Sciences University, Gandhinagar, India, for providing necessary facilities at University. One of the authors, Astitva Anand is thankful to UGC, New Delhi for the Award of Senior Research Fellow-Rajiv Gandhi National Fellowship.

\section{CONFLICT OF INTEREST}

The authors declare that there is no conflict of interests regarding the publication of this article.

\section{REFERENCES}

1. A. Yardley-Jones, D. Anderson and D.V. Parke, Br. J. Ind. Med., 48, 437 (1991).

2. G.F. Kalf and C.A. Snyder, Crit. Rev. Toxicol., 100, 293 (1987).

3. L.A. Wallace, Environ. Health Perspect., 104(Suppl 6), 1129 (1996); https://doi.org/10.1289/ehp.961041129.

4. IARC, IARC Monogr. Eval. Carcinog. Risk Chem. Hum., 100, 249 (1987).

5. ACGIH, Appl. Occup. Environ. Hyg., 5, 453 (1990); https://doi.org/10.1080/1047322X.1990.10389674. 
6. WHO, International Programme on Chemical Safety (IPCS): BenzenePoisons Information Monograph, p. 63 (1993).

7. K. Rahman, S. Aziz, K. Narasimhan and W. Owens, Am. J. Med. Sci., 338, 433 (2009); https://doi.org/10.1097/MAJ.0b013e3181b7f2a3.

8. N. Barbera, G. Bulla and G. Romano, J. Forensic Sci., 43, 14396J (1998); https://doi.org/10.1520/JFS14396J.

9. ATSDR, Agency Toxic Subst. Dis. Registry, p. 438 (2007).

10. T.J. Atkinson, Int. J. Hyg. Environ. Health, 212, 1 (2009); https://doi.org/10.1016/j.ijheh.2007.09.013.

11. S. Waidyanatha, N. Rothman, G. Li, M.T. Smith, S.M. Rappaport and S. Yin, Anal. Biochem., 327, 184 (2004); https://doi.org/10.1016/j.ab.2004.01.008.

12. Q. Qu, A.A. Melikian, G. Li, R. Shore, L. Chen, B. Cohen, S. Yin, M.R. Kagan, H. Li, M. Meng, X. Jin, W. Winnik, Y. Li, R. Mu and K. Li, Am. J. Ind. Med., 37, 522 (2000); https://doi.org/10.1002/(SICI) 1097-0274(200005)37:5<522::AIDAJIM8>3.0.CO;2-G.

13. R. Snyder and C.C. Hedli, Environ. Health Perspect., 104(Suppl 6), 1165 (1996); https://doi.org/10.1289/ehp.961041165.

14. D. Schrenk, A. Orzechowski, L.R. Schwarz, R. Snyder, B. Burchell, M. Ingelman-Sundberg and K.W. Bock, Environ. Health Perspect., 104(Suppl. 6), 1183 (1996); https://doi.org/10.1289/ehp.961041183.

15. P.J. Kerzic, W.S. Liu, M.T. Pan, H. Fu, Y. Zhou, A.R. Schnatter and R.D. Irons, Chem. Biol. Interact., 184, 182 (2010); https://doi.org/10.1016/j.cbi.2009.12.010.

16. H.A. Khan, Croat. Chem. Acta, 79, 169 (2006).
17. M.R. Lovern, C.E. Cole and P.M. Schlosser, Crit. Rev. Toxicol., 31, 285 (2001); https://doi.org/10.1080/20014091111703.

18. A. Anand, M.S. Dahiya and R. Agarwal, J. Planar Chromatogr. Mod. $T L C, \mathbf{3 0}, 474$ (2017); https://doi.org/10.1556/1006.2017.30.6.3.

19. T. Chauhan, T. Bhatia, M.K. Gupta, P. Pandey, V. Pandey, P.N. Saxena and M.K.R. Mudiam, J. Chromatogr. B Analyt. Technol. Biomed. Life Sci., 1001, 66 (2015); https://doi.org/10.1016/j.jchromb.2015.07.027.

20. W.F. Greenlee, J.P. Chism and D.E. Rickert, Anal. Biochem., 112, 367 (1981); https://doi.org/10.1016/0003-2697(81)90307-9.

21. H. Schad, F. Schäfer, L. Weber and H.J. Seidel, J. Chromatogr. A, 593, 147 (1992); https://doi.org/10.1016/0021-9673(92)80279-4.

22. M.P. Elie, M.G. Baron and J.W. Birkett, Analyst, 137, 255 (2012); https://doi.org/10.1039/C1AN15825B.

23. N. Rothman, W.E. Bechtold, S.N. Yin, M. Dosemeci, G.L. Li, Y.Z. Wang, W.C. Griffith, M.T. Smith and R.B. Hayes, Occup. Environ. Med., 55, 705 (1998); https://doi.org/10.1136/oem.55.10.705.

24. S. Chu and R.J. Letcher, Anal. Chem., 81, 4256 (2009); https://doi.org/10.1021/ac8027273.

25. J. Wu, R. Hu, J. Yue, Z. Yang and L. Zhang, J. Chromatogr. A, 1216, 1053 (2009); https://doi.org/10.1016/j.chroma.2008.12.054. 